\title{
Analysis and action: The political will and public will approach
}

\section{Authors: Amber N. W. Raile, Eric D. Raile, and Lori A. Post}

This is a postprint of an article that originally appeared in Action Research on May 2018. The final version can be found at https://dx.doi.org/10.1177/1476750318772662.

Raile, Amber N. W. , Eric D. Raile, and Lori A. Post. "Analysis and action: The political will and public will approach." Action Research (May 2018). DOI:10.1177/1476750318772662. 


\title{
Analysis and action: The political will and public will approach
}

\author{
Amber NW Raile \\ Jake Jabs College of Business \& Entrepreneurship, \\ Montana State University, Bozeman, MT, USA
}

\section{Eric D Raile}

Department of Political Science,

Montana State University, Bozeman, MT, USA

\section{Lori A Post}

Buehler Center for Health Policy and Economics, Northwestern University, Evanston, IL, USA

\begin{abstract}
Addressing complex social problems requires the implementation of public policies in support of positive social change efforts. Both political will and public will are crucial elements of such efforts. This article details an approach for analysis and action consistent with other action research approaches that facilitators can use in analyzing and subsequently helping to build political will and public will to address social problems. This article outlines a basic toolkit for action researchers working in the public policy arena. Four basic and iterative tasks, based on formal conceptual definitions of political will and public will, make up this approach for analysis and action. These tasks are stakeholder identification, assessment of stakeholder views of problems and solutions, alignment of problem and solution understandings, and the building of firm commitments and mutual accountability. Action researchers working to bring about positive social change through public policy can use this approach to structure their efforts.
\end{abstract}

\section{Keywords}

Political will, public will, public policy

\section{Corresponding author:}


Addressing complex social issues affecting communities or societies requires collective action and coordinated commitment and often entails short-term tradeoffs and sacrifices. As with change in any social system, enacting policy to deal with serious social issues is difficult. Too often, attempts at change fail to incorporate views of all relevant stakeholders and to consider how varied interpretations, interests, and language affect perceptions of social problems and policy solutions (Cohen, March, \& Olsen, 1972; Edelman, 2001; Eyestone, 1978; Kingdon, 2003; Peters, 2005; Rochefort \& Cobb, 1994; Spector \& Kitsuse, 2000; Stone, 2012). This article combines the conceptual definitions of political will (Post, Raile, \& Raile, 2010) and public will (Raile, Raile, Salmon, \& Post, 2014) to present the political will and public will (PPW) approach to analysis and action and explains how action researchers can use this approach to facilitate policymaking efforts. The PPW approach is a way to address social issues that require large-scale change and policy creation or reform.

The PPW approach complements action research (AR) metamethodology, with a specific focus on addressing public policy issues. Consistent with Dick's (2015) characterization of AR as a metamethodology, the PPW approach provides a "cyclic iteration between action and reflection that confers great flexibility, increasing its relevance in complex situations" (p. 440). The approach is meant to provide a toolkit of sorts to facilitate the flexible integration of established tools and ideas from practitioners and scholars. Focusing on how communication processes contribute to common problem and solution understandings across groups of political and public stakeholders, the approach lays out a systematic, integrated, and evidence-based process for social change that allows for strong context dependence (i.e., places, issues, understandings). Further, the approach emphasizes the benefits for mutual accountability (i.e., stakeholders holding each other jointly responsible for commitments) of identifying and involving stakeholders early and of utilizing tools that produce shared understandings. Finally, the approach integrates thinking about PPW in a way that recognizes the importance of both to social change efforts.

The PPW approach for analysis and action guides facilitators through the following questions in order to assess and help build, as needed, PPW:

1. Who are the key political and public stakeholders in the issue area?

2. How do those stakeholders view the problem and potential solutions?

3. What can be done to facilitate alignment of stakeholder views of problems and solutions?

4. How can meaningful mutual accountability among stakeholders be reached for clear, shared commitments?

Through observation-based analysis, the procedures allow for further understanding of PPW related to a specific issue in context. The information gathered shapes the choice of techniques for facilitating understanding and for holding stakeholders mutually accountable. Attending to these tasks in a comprehensive 
and connected manner improves the chances of success, though facilitators should be aware of the potential nonlinear and iterative nature of this process.

Although the PPW approach is not exclusively for developing contexts, this article offers ideas more specifically to facilitators looking to apply the PPW approach and its AR elements in development projects. Top-down aid programs have traditionally been dominant for various reasons (e.g., legacy of colonialism, lack of understanding of how to deal with diversity within a country, cultural obstacles). However, momentum has built recently for programs that engage broader stakeholders as active participants. As a result, some early applications of the PPW approach have been funded by the United States Agency for International Development for the Feed the Future $(\mathrm{FtF})$ initiative. Both FtF and the PPW approach emphasize stakeholder involvement, participatory communication techniques, and locally led establishment of priorities and change efforts based on a recognition that mutual accountability is easier to achieve if it is a priority from the beginning of the policymaking processes. The PPW approach is meant to provide guidance that links AR and development programs, specifically work that aims to affect public policymaking. Although the PPW approach as applied so far resides closer to the middle of the continuum between consultation and full participation, the PPW approach is similar to AR in their shared perspective that "knowledge creation ... arises in the context of practice and requires researchers to work with practitioners" (Bradbury-Huang, 2010, p. 93). Thus, this guide is provided with a focus on how facilitators can apply AR approaches to support development initiatives aiming to generate policy.

This article provides an overview of the PPW approach. First, the article provides background information about the concepts of PPW and about the benefits of the PPW approach. Next, the tasks and potential tools associated with the approach are examined. Finally, a summary and consideration of the PPW approach for analysis and action concludes the article.

\section{Political will and public will}

When discussing social change efforts connected to policy, we often hear about the lack of political will or public will to address the problem or to adopt a particular policy solution. But what are political will and public will? The PPW approach to research started by defining these constructs in a way that would allow for analysis and action.

- Political will crosses a meaningful threshold when "a sufficient set of decision makers with a common understanding of a particular problem on the formal agenda is committed to supporting a commonly perceived, potentially effective policy solution" (Post et al., 2010, p. 659).

- Public will similarly becomes meaningful when "a social system has a shared recognition of a particular problem and resolves to address the situation in a particular way through sustained collective action" (Raile et al., 2014, p. 105). 
These definitions share a perspective on the concept of will, which is almost always the intentionality of a collective of people. Systems thinking seeks to understand contexts as a whole made up of interrelated, interdependent parts and is characterized by dynamic complexity that arises out of multiple causes and effects over time. Similarly, "AR is premised on the notion that the reality we confront is a complex, dynamic, interactive open system" (Greenwood, 2015, p. 207). Directly linked to the notion of public will, a social system is "a set of interrelated units that are engaged in joint problem solving to accomplish a common goal. The members or units of a social system may be individuals, informal groups, organizations, and/or subsystems" (Rogers, 2003, p. 23). Systems AR characterizes "change as highly relational and dependent on the deeper dynamics of a whole system" (Burns, 2014, p. 5). The PPW definitions alert facilitators to complexity by characterizing stakeholders through a systems lens.

As noted by action researchers, "all knowers have knowledge fundamental to the design and execution of any social change process" (Greenwood, 2015, p. 199). Policy change efforts can unintentionally marginalize research or realworld complexities or both. Further, the PPW approach recognizes that PPW are strongly dependent on a configuration of contexts like places, issues, and understandings. This approach is consistent with the AR beliefs that "all knowledge and action are ultimately contextual and we acknowledge that complexity" (Greenwood, 2015, p. 207). The PPW assessment procedures treat local expertise and scholarly knowledge as instrumental in achieving true longterm change.

Efforts originating with the government often produce laws or regulations that demand change, but social pressures, cultural norms, engrained habits, and systemic barriers can limit citizen adherence to such policies (Post et al., 2010). Similarly, social change efforts driven by citizens and other nongovernmental entities will flounder if government opposes or refuses to reinforce the change (Raile et al., 2014). PPW are dynamic in that they change and modify in reaction to one another over time. A call for change may come from the voices of citizens or the speeches of policy makers, but lasting, meaningful social change relies on the alignment of both PPW to alter societal structures and practices. Ultimately, though limited counterexamples might exist, both PPW are necessary to the success of policies focused on a particular issue regardless of a country's political and governmental systems. Ideal situations for social change emerge over time and through complex intentional and unintentional interactions between PPW. These interactions modify social and structural responses to particular social problems. When both PPW are high, the political system and key publics have converged on problem and solution understandings. Because both political and public stakeholders are necessary for successful change, parallel definitional structures for the two concepts in the PPW approach allow for comparison and examination of interactions between PPW related to a given social issue. 


\section{Tasks and tools}

Consistent with AR, the PPW approach for analysis and action promotes a "collaborative democratic partnership" to problem solving (Coghlan \& Brannick, 2005 p. 3). Through collaboration, stakeholders can combine what they know about effective strategies and techniques. The PPW approach outlined here is being used in conjunction with U.S. government-funded research supporting agricultural innovations, new technologies, and improved policies in climatesmart agriculture and nutrition. The short-term incentives and risk calculations for smallholder agricultural producers and policymakers often work against adoption of such innovations and technologies. Not surprisingly given the complexity of the task, successful implementation of policies across countries has been a challenge faced by the FtF initiative (Feed the Future, 2013). Without PPW for change, initiatives are unlikely to have the desired impact. The remainder of this article outlines how facilitators can utilize previously articulated definitions of PPW to effect policy change.

As shown in Table 1, four key tasks consistent with the components of the conceptual definitions of the PPW approach are instrumental in building PPW for targeted policy or other social change in a way that produces mutual accountability. The four tasks are as follows:

- Task 1: Identify key political and public stakeholders in the issue area;

- Task 2: Determine existing problem and solution understandings;

Table I. Mapping definitional components to tasks.

\begin{tabular}{|c|c|c|c|}
\hline & $\begin{array}{l}\text { Political will (Post, } \\
\text { Raile, \& Raile, 2010) }\end{array}$ & $\begin{array}{l}\text { Public will (Raile } \\
\text { et al., 20I4) }\end{array}$ & $\begin{array}{l}\text { Political will and public will } \\
\text { approach tasks }\end{array}$ \\
\hline Stakeholders & $\begin{array}{l}\text { Sufficient set of deci- } \\
\text { sion makers }\end{array}$ & Specific social system & $\begin{array}{l}\text { Task I: Identify key political } \\
\text { and public stakeholders } \\
\text { in the issue area }\end{array}$ \\
\hline $\begin{array}{r}\text { Existing } \\
\text { views }\end{array}$ & $\begin{array}{l}\text { Understanding of a } \\
\text { particular problem } \\
\text { and solution }\end{array}$ & $\begin{array}{l}\text { Recognition of a particular } \\
\text { problem and solution }\end{array}$ & $\begin{array}{l}\text { Task 2: Determine existing } \\
\text { problem and solution } \\
\text { understandings }\end{array}$ \\
\hline Alignment & $\begin{array}{l}\text { Common understanding } \\
\text { of a particular prob- } \\
\text { lem with a commonly } \\
\text { perceived, potentially } \\
\text { effective } \\
\text { policy solution }\end{array}$ & $\begin{array}{l}\text { Shared recognition of a } \\
\text { particular problem that } \\
\text { should be resolved in a } \\
\text { particular way }\end{array}$ & $\begin{array}{l}\text { Task 3: Facilitate alignment } \\
\text { of problem and solution } \\
\text { understandings, } \\
\text { as necessary }\end{array}$ \\
\hline Commitment & $\begin{array}{l}\text { Committed } \\
\text { to supporting }\end{array}$ & $\begin{array}{l}\text { Resolve to address the sit- } \\
\text { uation through sustained } \\
\text { collective action }\end{array}$ & $\begin{array}{l}\text { Task 4: Build firm commit- } \\
\text { ments and mutual } \\
\text { accountability }\end{array}$ \\
\hline
\end{tabular}


- Task 3: Facilitate alignment of problem and solution understandings, as necessary; and

- Task 4: Build firm commitments and mutual accountability.

These tasks are listed roughly in order, though some repetition and combination are often necessary in an iterative process. Tasks 1 and 2 entail measurement of system characteristics, while Tasks 3 and 4 involve communication and accountability mechanisms. Completing the initial two tasks will help facilitators pinpoint the specific contexts within which they seek to make change. The following subsections articulate how the tasks allow for both generality and flexibility.

The PPW approach integrates tools and ideas from communication, political science, psychology, sociology, business, and economics. Table 2 provides examples of how specific research, analytical, and communication tools map to different circumstances within each of the four tasks. Table 2 is not meant to be an exhaustive list of potential techniques. References to these tools were added in the same spirit that other references are presented throughout this article-with the hope that those looking to try the PPW approach will consider these ideas and experiences and incorporate them into attempts to address specific problems through policy. This "toolkit" directs facilitators toward larger works and bodies of literature that can provide additional help with specific issues that might arise in specific contexts. Facilitators are viewed as stakeholders in the process who bring their own skills and insights along with other stakeholders. As facilitators work through each task, the contexts and desired outcomes should inform the methodological tool(s) used. No single methodology can address all the tasks necessary for interventions into systems (Behrens \& Foster-Fishman, 2007). Further, multiple tools might be necessary for a given task. The PPW approach is meant to facilitate progress toward public policy aimed at addressing complex social problems by providing a framework for applying those "tools" in a cohesive and systematic manner. The following subsections walk through each task in turn.

\section{Task I: Identifying stakeholders}

The first task is to identify the key stakeholders in the issue area, which at a minimum means determining who must be involved in the change effort. Consistent with systems AR, identifying and including stakeholders with a diversity of perspectives is vital for this task (Burns, 2014). Taking a systems change approach means that facilitators should focus on aspects of the system, like subsystems, that are pertinent to the issue at hand (Parsons, 2007), which might mean looking at existing advocacy coalitions and policy subsystems (Jenkins-Smith, Nohrstedt, Weible, \& Sabatier, 2014). Stakeholder analysis (Brugha \& Varvasovszky, 2000) can be helpful in identifying these groups.

On the political side, facilitators must identify both necessary and sufficient decision makers. Necessary actors are ones whose participation is crucial to success or ones who can block the change effort. A sufficient set of actors is one that 


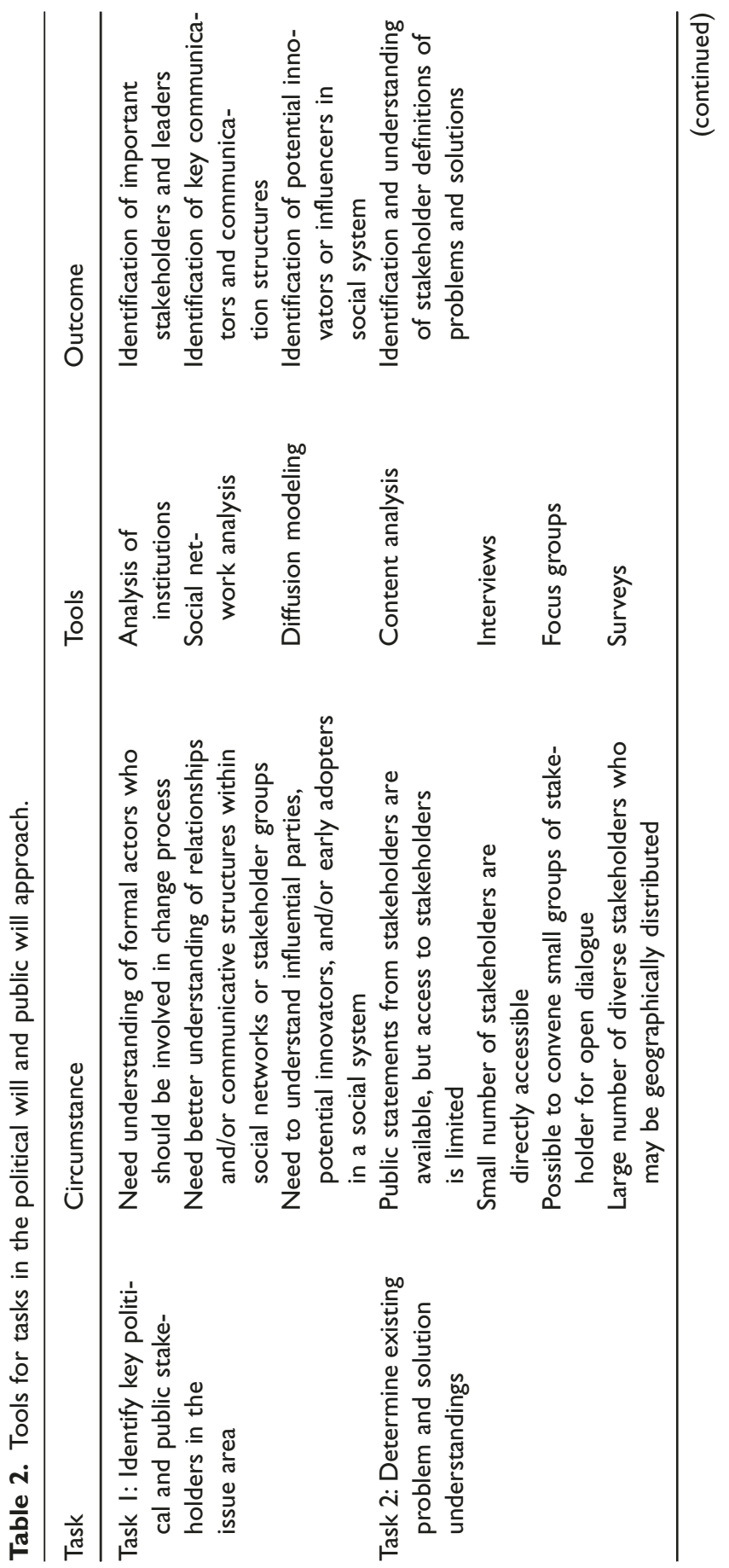




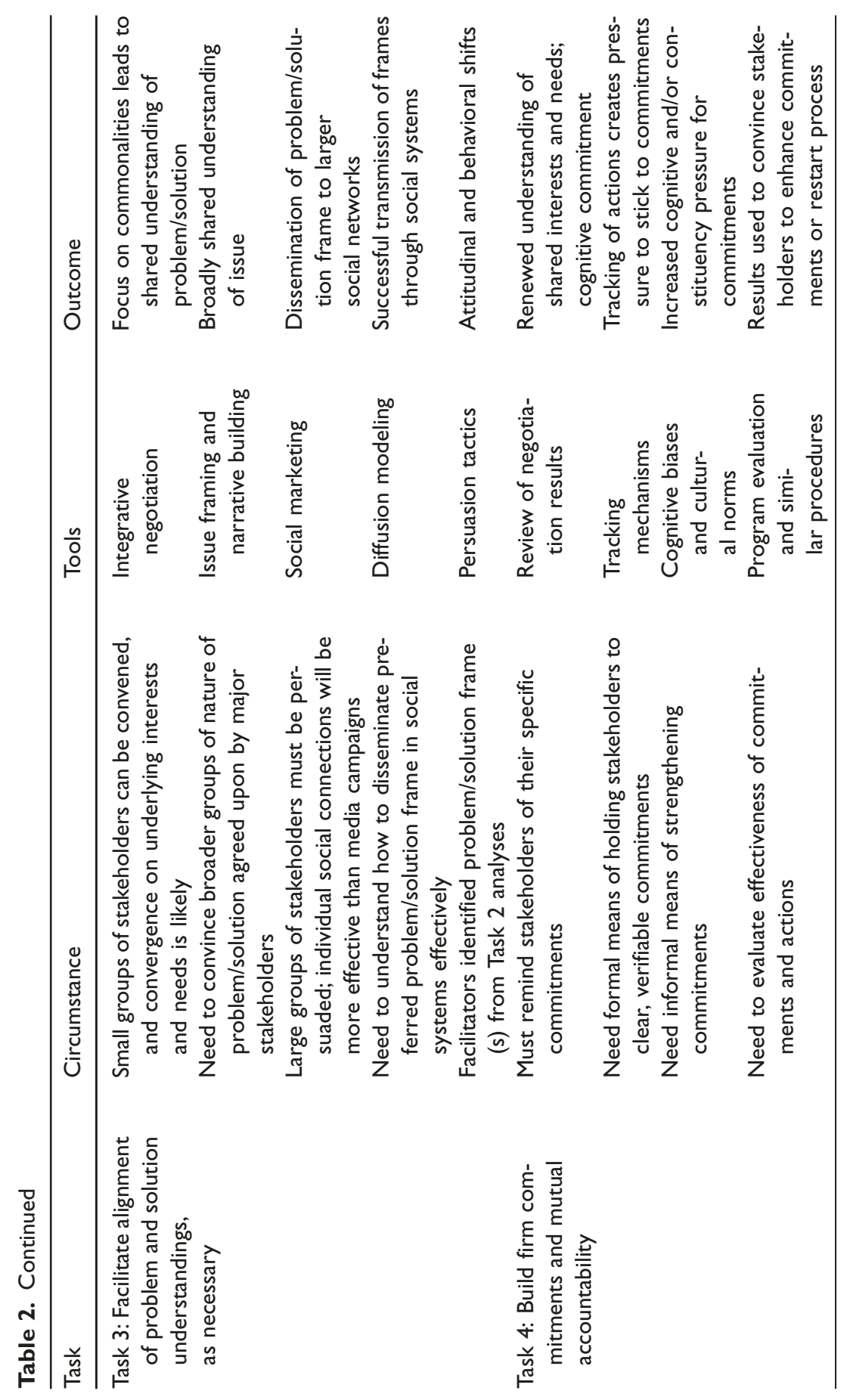


contains the right combination of political actors for the change effort to be successful. Analysis of political institutions (i.e., the rules that structure politics and governance) can aid greatly in the identification of relevant decision makers. Identifying decision makers may be easy in an authoritarian regime, though sometimes the real decision makers remain hidden behind puppet figures. This analysis needs to take into account the particular mix of political institutions. Some of these institutions are more formalized, like the legal organization of the government, while other important institutions are less formal, like political parties and coalitions.

A similar evaluation of the public side involves identification of nongovernmental actors who are crucial to and sufficient for an initiative's success. This exercise can be complicated, as publics come in different shapes and sizes, with different levels of cohesion, formality, and resolve (Raile et al., 2014). Furthermore, multiple publics exist at any given time, none of which need represent a majority of the population to be meaningful (Raile et al., 2014); the wills of certain "publics" can be highly influential in policymaking (Jenkins-Smith et al., 2014; Sabatier \& Jenkins-Smith, 1993). Communication, which is the foundation of institutions and publics (Cornelissen, Durand, Fiss, Lammers, \& Vaara, 2015), might take place within or across levels (e.g., interpersonal, group, organizational) of interaction. Individuals play multiple roles within a social context and can be members of multiple publics (Liederman, Wolf, \& York, 1997). The potential existence of many different "publics" and the fact that individuals often have multiple meaningful identities complicates identification of publics (for further discussion, see Raile et al., 2014).

One approach to understanding social systems is as a collection of individuals engaged in communicative activities (e.g., Craig, 1999; Underwood \& Frey, 2008). Understanding how information flows among entities in a social or political system can help facilitators understand the social construction of problems and corresponding solutions. Understanding information flows means examining communication networks, which are "the patterns of contact between communication partners that are created by transmitting an exchanging messages through time and space" (Monge \& Contractor, 2001, p. 440). Such analysis can help facilitators understand how different individuals are connected to one another, how information about certain topics flows throughout a social system, and where social connections among stakeholders exist. By understanding who talks to whom and about what, facilitators can identify potential partners and gain insight into channels for dissemination of information about a particular social problem. For example, social network analysis and diffusion modeling are social science tools for measuring characteristics of social structures. The social network analyst is responsible for setting the network boundaries and the types of relations to be studied (Foster-Fishman \& Behrens, 2007; Knoke \& Yang, 2007; Shumate \& Contractor, 2013). Ultimately, the network structure depends heavily on such choices, which should be driven by the necessary information in a particular context. Similarly, diffusion modeling (Rogers, 2003) can help identify influential parties, potential innovators, or early adopters in a social system. Worth noting is that social 
network analysis can be difficult if facilitators do not first gain the trust of other stakeholders in the social system.

Efforts within this task overall should result in the identification of relevant stakeholders within government, the identification of key public stakeholders, and an understanding of the relationships among stakeholders. Further, the analyses will help identify leaders and likely routes for the spread of innovations and information, which will aid in accomplishing the remaining tasks. In practice, this analysis must combine with Task 2 below, as communication is part of what determines the existence of a social system.

\section{Task 2: Assessing problem and solution understandings}

The second task is to assess how stakeholders understand problems and solutions and the linkages between them. Change to a system "requires understanding different perspectives concerning the problem situation" (Foster-Fishman, Nowell, \& Yang, 2007). Certainly, problems can have relatively objective characteristics associated with them, like statistics, monetary costs, and systematic observations. However, the decision of whether to accept any given issue as a problem, meaning it needs to be addressed (see discussion in Baumgartner \& Jones, 2015; Peters, 2005), is largely a result of social construction (Brydon-Miller, Greenwood, \& Maguire, 2003; Spector \& Kitsuse, 2000; Stone, 2012). In other words, individuals and groups in society determine that a situation is a problem as a consequence of communicative interactions and the making of claims. The same applies to understandings of solutions and their linkages to these problems. Social construction helps explain why some problems that seem more severe by objective criteria get ignored in favor of others.

Thus, this task involves assessing how stakeholders view the issue and the extent to which they see the situation as problematic. Importantly, certain solutions seem more appropriate for certain types of problems. Stakeholders with varying perspectives on the problem will perceive different solutions as appropriate, especially for more entrenched problems (Burns, 2014, p. 11). Change is easier if key stakeholders share the same problem understanding and align it with a single, commonly understood solution. The often socially constructed nature of problems and solutions (Borah, 2011; Chong \& Druckman, 2007; Spector \& Kitsuse, 2000; Stone, 2012) means that inclusive and nuanced communication approaches are often necessary. In line with this observation, the architects of the New Public Service have argued "that public service should focus on creating opportunities for citizenship by forging trusting relationships with members of the public and working with them to define public problems, develop alternatives, and implement solutions" (Denhardt \& Denhardt, 2015, p. 665). Similarly, the PPW approach has an overriding focus on the importance of broad groups of stakeholders agreeing upon aligned problem and solution understandings.

Gaining understanding of stakeholder views of problems and solutions can proceed through two potential mechanisms: asking stakeholders directly and/or 
examining available statements made by stakeholders. As shown in Table 2, facilitators have a number of tools available for collecting such data. These tools include ethnography, interviews, group interviews, focus groups, surveys, and content analysis (see Brians, Willnat, Manheim, \& Rich, 2011; Bryman, 2016; Kruegar \& Casey, 2015). A few key considerations, including the number and dispersion of stakeholders, the depth and breadth of the information needed, and available resources, should guide the selection. Facilitators are looking for divergence or convergence in the language, symbols, etc., used to identify problems and solutions. The analysis can also assess the volume and prominence of the discussion. Facilitators can ask directly about the relative importance of problems as well. Consistent with soft systems methodology, the goal is "gaining insight into the different stakeholder interpretations of the problem situation and recognizing that the feasibility of solving a problem depends largely on how many and which perspectives are selected for understanding the problem" (Foster-Fishman et al., 2007, p. 200). The result of these efforts should be a comprehensive catalog of stakeholder perceptions of problems and solutions, as well as their relative weights and linkages.

\section{Task 3: Facilitating shared understanding}

The goal of the third task is to achieve specific, shared stakeholder perceptions of a problem and a solution. The facilitators (and other partners) must identify the optimal techniques based on the information collected for Tasks 1 and 2. The techniques effective in generating support and mutual accountability (Task 4) require an understanding of stakeholders (Task 1) and their needs and interests (Task 2) or "points of connection between people within a system" (Burns, 2014, p. 12). As a result, inclusiveness and dialogue among key stakeholders can lead to a coherent frame of the problem and its solution (Foster-Fishman \& Behrens, 2007). Facilitators should consider whether solutions are ones for which capacity exists or can be built and are ones that have a reasonable chance of being effective (Post et al., 2010; Raile et al., 2014). Finally, facilitators must continuously assess the progress and effectiveness of the techniques and make adjustments as necessary in an iterative manner. The emphasis on social construction in the PPW approach, touched on in Task 2, is consistent with AR approaches (Greenwood, 2015).

Specifically, the constitutive model of communication, which "conceptualizes communication as a constitutive process that produces and reproduces shared meaning" (Craig, 1999, p. 125), is consistent with the AR emphasis on constructivism (Greenwood, 2015). Because the constitutive model is fundamental to theories of communication, the approaches in Task 3 come primarily from the field of communication. The appropriate techniques depend in part on the number of stakeholders (see Table 2). With a relatively small number of key stakeholders, facilitators might use integrative negotiation, which emphasizes shared interests and needs (Fisher, Ury, \& Patton, 2011). Focusing on shared interests (e.g., acting in line with strongly held beliefs or values) and needs can lead stakeholders to 
common ground. Integrative negotiation can also open a dialogue and facilitate mutual accountability (Task 4). This dialogue should help stakeholders see similarities and differences in problem and solution understandings. With a larger group of stakeholders, facilitators might use existing issue frames and narratives that can incorporate particular understandings of problems and solutions. Issue (or policy) frames potentially include many components, among which are ways to categorize and describe a problem and link that problem to a solution (Borah, 2011; Chong \& Druckman, 2007; Entman, 1993; Nelson, 2004; Peters, 2005). However, care must be taken to ensure that the intended audience sees the messenger as trustworthy and credible (Chong, 1993; Druckman 2001a, 2001b; Druckman \& Nelson, 2003). Narratives, which are persuasive storytelling structures that might be used within a particular frame, are built around literary elements like settings, plot, characters, and morals (Jones, Shanahan, \& McBeth, 2014). Discourse provides opportunities to facilitate change (Foster-Fishman \& Behrens, 2007, p. 195). Regardless of the number of stakeholders involved, the goal is to arrive at shared understanding.

Facilitators might also consider diffusion of innovation (Rogers, 2003) or social marketing (Andreasen, 2006) as techniques when the number of relevant stakeholders or stakeholder groups is large. "Diffusion is the process in which an innovation is communicated through certain channels over time among members of a social system" (Rogers, 2003, p. 5). Diffusion of innovation highlights the importance of understanding the social system and different reactions to innovations. Facilitators might help to generate PPW for a particular problem/solution combination by identifying key individuals within a social system who are likely to be open to innovation and are likely to move through the innovation-decision process (Rogers, 2003) relatively quickly. Consistent with Coffman's (2002) work on public will campaigns, Andreasen (2006) proposes social marketing as a way of encouraging individual awareness of social issues and willingness to act. Traditionally, both diffusion of innovation and social marketing tend to be more directive in that a particular problem and/or solution are preselected. The same is true of a range of persuasion techniques (e.g., see Albarracín, Johnson, \& Zanna, 2005; Cialdini, 2006; Fishbein \& Ajzen, 2010; Gass \& Seiter, 2013), which primarily work by activating cognitive biases (see Kahneman, 2011) or by imposing cultural costs (see Hofstede, Hofstede, \& Minkov, 2010).

With large numbers of stakeholders, the PPW approach's emphasis on social construction through negotiation among stakeholders becomes more difficult. However, facilitators can still focus on disseminating messages that have been agreed upon by stakeholder group leaders. In developing contexts, and particularly within development aid programs, broad implementation of innovations requires a scaling up process. This scaling up typically requires some degree of persuasion, as building change from the bottom up in all locations is prohibitively expensive in terms of time and other resources. The PPW approach advocates for persuasion efforts based on logic and collaboration rather than compliance-gaining techniques. Such efforts should be as inclusive as possible of local stakeholders. 


\section{Task 4: Building commitments and mutual accountability}

The fourth task involves the building of firm commitments and mutual accountability. The mutual accountability that arises with mutual problem and solution understanding is vital in producing change (see Steer \& Wathne, 2009). Mutual accountability falls apart when stakeholders have different expectations and fail to see shared interests and interdependence. Without strong mutual accountability mechanisms, stepping back from the social and policy changes necessary to address complex issues is simply too easy and too tempting. The PPW approach enhances the likelihood of mutual accountability succeeding by dealing with these underlying risks.

Similar to the interactions between PPW discussed previously, Task 4 aims to attend to system dynamics.

Changes which do not shift the underlying system dynamic are likely to be short lived (unsustainable) because the system dynamic is created by a network of powerful forces and inter-relationships which carve channels for behaviour (economic, social and cultural) which are hard to break from. (Burns, 2014, p. 6)

To some extent, this task exceeds the PPW definitions by going beyond intentions into outcomes or manifestations of will. However, this task also helps to validate continuing existence of PPW and is also crucial to the complete work of facilitators. Certain outcomes of PPW, like legislation or agreements, might intervene between Tasks 3 and 4 . If involved in the crafting of such outcomes, facilitators can boost later mutual accountability efforts by ensuring that stakeholders make clear and verifiable commitments along the way. In any case, the PPW approach presupposes that the shared understanding in Task 3 involves goal setting and direction setting of some sort. Clear commitments are a necessary precursor for many of the activities envisioned under Task 4. Competent completion of Tasks $1-3$ will increase the quality and strength of mutual accountability efforts and will produce a clear idea of the stakeholders who should be the focus of these efforts.

The tools and approaches listed for Task 4 in Table 2 are means of tracking clear commitments and of otherwise developing mutual accountability. For example, reviewing earlier outcomes, like the results of integrative negotiation efforts, can remind stakeholders of their role in coming to agreement. This reminder can lock stakeholders cognitively into their commitments. Such a review can also reiterate how action will serve the stakeholders' interests and needs. Further, facilitators can establish transparent tracking mechanisms that will show all stakeholders (and maybe the general public or other external groups) that stakeholders are honoring their commitments in a timely manner. Accordingly, another activity that can be helpful under Task 4 is evaluation of the effectiveness of stakeholder commitments. In other words, are the commitments producing the desired results? Although a sizeable topic on its own, standard program evaluation 
tools (and other monitoring tools like system dynamics modeling, benefit-cost analysis, performance monitoring, customer satisfaction evaluation, and risk assessment (see Hirsch, Levine, \& Miller, 2007; Kraft \& Furlong, 2014; Posavac, 2011) are capable of providing necessary feedback.

Real-world dynamics can change situations and make the work done in Tasks 1-4 outdated. Facilitators may need to make adjustments as events unfold. In accord with the systems theory tradition in political science (see Easton, 1965) and with systems approaches more generally, the PPW approach allows for feedback. The results of Tasks 1-4 should feed new inputs such as information back into the system. Ongoing evaluation following a holistic model such as fourth generation evaluation (Guba \& Lincoln, 1989), which is consistent with the stakeholder considerations and comprehensive method taken by the PPW approach, can help ensure that all the tasks are aligned. If they are not aligned, facilitators can revisit particular tasks or restart the process.

\section{Conclusion}

This article details how facilitators can apply the PPW approach for analysis and action to address social issues. Because long-term change within complex social systems takes considerable time, effort, and other resources, no single solution delivers success universally. Efforts for long-term change must account for the complexity of social systems and must employ pragmatic AR techniques. The PPW approach details four relatively intensive tasks within an iterative process that is not necessarily linear. In research using the PPW approach in complex situations thus far, the approach has been useful and allowed for the identification of some practices that increase its utility. The hope in disseminating this toolkit is that others will apply it in new contexts and in new ways, thereby allowing for improvements and enhancing the utility and effectiveness of the approach.

\section{Declaration of conflicting interests}

The author(s) declared no potential conflicts of interest with respect to the research, authorship, and/or publication of this article.

\section{Funding}

The author(s) disclosed receipt of the following financial support for the research, authorship, and/or publication of this article: This work was supported by the United States Department of Agriculture through the United States Agency for International Development. The views and conclusions in this article are those of the authors and do not necessarily represent the positions of these organizations. 


\section{References}

Albarracín, D., Johnson, B. T., \& Zanna, M. P. (2005). The handbook of attitudes. New York, NY: Psychology Press.

Andreasen, A. R. (2006). Social marketing in the 21st century. Thousand Oaks, CA: SAGE.

Baumgartner, F. R., \& Jones, B. D. (2015). The politics of information: Problem definition and the course of public policy in America. Chicago, IL: University of Chicago Press.

Behrens, T. R., \& Foster-Fishman, P. G. (2007). Developing operating principles for systems change. American Journal of Community Psychology, 39, 411-414. doi:10.1007/ s10464-007-9106-3

Borah, P. (2011). Conceptual issues in framing theory: A systematic examination of a decade's literature. Journal of Communication, 61, 246-263. doi:10.1111/j.14602466.2011.01539.x

Bradbury-Huang, H. (2010). What is good action research? Why the resurgent interest? Action Research, 8, 93-109. doi:10.11777/1476750310362435

Brians, C. L., Willnat, L., Manheim, J. B., \& Rich, R. C. (2011). Empirical political analysis (8th ed.). Boston, MA: Longman.

Brugha, R., \& Varvasovszky, Z. (2000). Stakeholder analysis: A review. Health Policy and Planning, 15, 239-246. doi:10.1093/heapol/15.3.239

Brydon-Miller, M., Greenwood, D., \& Maguire, P. (2003). Why action research? Action Research, 1, 9-28. doi:10.1177/14767503030011002

Bryman, A. (2016). Social research methods (5th ed.). Oxford, England: Oxford University Press.

Burns, D. (2014). Systemic action research: Changing system dynamics to support sustainable change. Action Research, 12, 3-18. doi:10.1177/1476750313513910

Chong, D. (1993). How people think, reason, and feel about rights and liberties. American Journal of Political Science, 37(3), 867-899. doi:10.2307/2111577

Chong, D., \& Druckman, J. N. (2007). Framing theory. Annual Review of Political Science, 10, 103-126. doi:10.1146/annurev.polisci.10.072805.103054

Cialdini, R. B. (2006). Influence: The psychology of persuasion. New York, NY: Harper Business.

Coffman, J. (2002). Public communication campaign evaluation: An environmental scan of challenges, criticisms, practice, and opportunities. Cambridge, MA: Harvard Family Research Project.

Coghlan, D., \& Brannick, T. (2005). Doing action research in your own organization (2nd ed.). Thousand Oaks, CA: SAGE.

Cohen, M., March, J. G., \& Olsen, J. P. (1972). A garbage can model of organizational choice. Administrative Science Quarterly, 17, 1-25. doi:10.2307/2392088

Cornelissen, J. P., Durand, R., Fiss, P. C., Lammers, J. C., \& Vaara, E. (2015). Putting communication front and center in institutional theory and analysis. Academy of Management Review, 40, 10-27. doi:10.5465/amr.2014.0381

Craig, R. T. (1999). Communication theory as a field. Communication theory, 9, 119-161. doi:10.1111/j.1468-2885.1999.tb00355.x

Denhardt, J. V., \& Denhardt, R. B. (2015). The new public service revisited. Public Administration Review, 75, 664-672. doi:10.1111/puar.12347

Dick, B. (2015). Reflections on the SAGE Encyclopedia of Action Research and what it says about action research and its methodologies. Action Research, 13, 431-444. doi:10.1177/ 1476750315573593 
Druckman, J. N. (2001a). On the limits of framing effects: Who can frame? Journal of Politics, 63(4), 1041-1066. doi:10.1111/0022-3816.00100

Druckman, J. N. (2001b). The implications of framing effects for citizen competence. Political Behavior, 23(3), 225-256. doi:10.1023/A:1015006907312

Druckman, J. N., \& Nelson, K. R. (2003). Framing and deliberation: How citizens' conversations limit elite influence. American Journal of Political Science, 47(4), 729-745. doi:10.1111/1540-5907.00051

Easton, D. (1965). A systems analysis of political life. New York, NY: John Wiley \& Sons.

Edelman, M. (2001). The politics of misinformation. Cambridge, England: Cambridge University Press.

Entman, R. M. (1993). Framing: Toward clarification of a fractured paradigm. Journal of Communication, 43(4), 51-58. doi:10.1111/j.1460-2466.1993.tb01304.x

Eyestone, R. (1978). From social issues to public policy. New York, NY: Wiley.

Feed the Future. (2013, June). Progress scorecard. Retrieved from http://www.feedthefuture. gov/sites/default/files/resource/files/feed_the_future_scorecard_2013.pdf

Fishbein, M., \& Ajzen, I. (2010). Predicting and changing behavior: The reasoned action approach. New York, NY: Psychology Press.

Fisher, R., Ury, W., \& Patton, B. (2011). Getting to yes: Negotiating agreement without giving in. New York, NY: Penguin Books.

Foster-Fishman, P. G., \& Behrens, T. R. (2007). Systems change reborn: Rethinking our theories, methods, and efforts in human services reform and community-based change. American Journal of Community Psychology, 39, 191-196. doi:10.1007/s10464-007-9104-5

Foster-Fishman, P. G., Nowell, B., \& Yang, H. (2007). Putting the system back into systems change: A framework for understanding and changing organizational and community systems. American Journal of Community Psychology, 39, 197-215. doi:10.1007/s10464007-9109-0

Gass, R. H., \& Seiter, J. S. (2013). Persuasion, social influence, and compliance gaining (5th ed.). New York, NY: Routledge.

Greenwood, D. J. (2015). An analysis of the theory/concept entries in the SAGE Encyclopedia of Action Research: What we can learn about action research in general from the encyclopedia. Action Research, 13, 198-213. doi:10.1177/ 1476750315573592

Guba, E. G., \& Lincoln, Y. S. (1989). Fourth generation evaluation. Newbury Park, CA: SAGE.

Hirsch, G. B., Levine, R., \& Miller, R. L. (2007). Using system dynamics modeling to understand the impact of social change initiatives. American Journal of Community Psychology, 39, 239-253. doi:10.1007/s10464-007-9114-3

Hofstede, G., Hofstede, G. J., \& Minkov, M. (2010). Cultures and organizations: Software of the mind (3rd ed.). New York, NY: McGraw-Hill Education.

Jenkins-Smith, H., Nohrstedt, D., Weible, C. M., \& Sabatier, P. A. (2014). The advocacy coalition framework: Foundations, evolution, and ongoing research. In Sabatier P. A. \& Weible C. M. (Eds.), Theories of the policy process (3rd ed., pp. 183-223). Boulder, CO: Westview Press.

Jones, M. D., Shanahan, E. A., \& McBeth, M. K. (2014). The science of stories: Applications of the narrative policy framework in public policy analysis. London, England: Palgrave Macmillan.

Kahneman, D. (2011). Thinking, fast and slow. New York, NY: Farrar, Straus, and Giroux. 
Kingdon, J. W. (2003). Agendas, alternatives, and public policies (2nd ed.). New York, NY: Longman.

Knoke, D., \& Yang, S. (2007). Social network analysis (2nd ed.). Thousand Oaks, CA: SAGE.

Kraft, M. E., \& Furlong, S. R. (2014). Public policy: Politics, analysis, and alternatives (5th ed.). Washington, DC: CQ Press.

Kruegar, R. A., \& Casey, M. A. (2015). Focus groups: A practical guide for applied research (5th ed.). Thousand Oaks, CA: SAGE.

Liederman, S. A., Wolf, W. C., \& York, P. (1997). Some thoughts about public will. Retrieved from Center for Assessment and Policy Development: http:/www.capd.org/ pubfiles/pub-1997-03-01.pdf

Monge, P. R., \& Contractor, N. S. (2001). Emergence of communication networks. In Jablin F. M. \& Putnam L. L. (Eds.), New handbook of organizational communication: Advances in theory, research, and methods (pp. 440-502). Thousand Oaks, CA: SAGE.

Nelson, T. E. (2004). Policy goals, public rhetoric, and political attitudes. Journal of Politics, 66, 581-605. doi:10.1111/j.1468-2508.2004.00165.x

Parsons, T. (2007). An outline of the social system. In Calhoun C., Gerteis J., Moody J., Pfaff S., \& Virk I. (Eds.), Classical sociological theory (3rd ed., pp. 502-522). Malden, MA: Wiley-Blackwell.

Peters, G. B. (2005). The problem of policy problems. Journal of Comparative Policy Analysis, 7, 349-370. doi:10.1080/13876980500319204

Posavac, E. J. (2011). Program evaluation: Methods and case studies (8th ed.). New York, NY: Routledge.

Post, L. A., Raile, A. N. W., \& Raile, E. D. (2010). Defining political will. Politics \& Policy, 38, 653-676. doi:10.1111/j.1747-1346.2010.00253.x

Raile, E. D., Raile, A. N. W., Salmon, C. T., \& Post, L. A. (2014). Defining public will. Politics \& Policy, 42, 103-130. doi:10.1111/polp.12063

Rochefort, D. A., \& Cobb, R. W. (1994). The politics of problem definition. Lawrence, KS: University of Kansas Press.

Rogers, E. M. (2003). Diffusion of innovations (5th ed.). New York, NY: Free Press.

Sabatier, P. A., \& Jenkins-Smith, H. C. (1993). Policy change and learning: An advocacy coalition approach. Boulder, CO: Westview Press.

Shumate, M., \& Contractor, N. S. (2013). Emergence of multidimensional social networks. In Linda L. Putnam \& Dennis K. Mumby (Eds.), SAGE handbook of organizational communication: Advances in theory, research, and methods (pp. 449-474). Thousand Oaks, CA: SAGE.

Spector, M., \& Kitsuse, J. I. (2000). Constructing social problems. Piscataway, NJ: Transaction Publishers.

Steer, L., \& Wathne, C. (2009). Mutual accountability at country level: Emerging good practice. Overseas Development Institute. London, England. Retrieved from https://www. odi.org/sites/odi.org.uk/files/odi-assets/publications-opinion-files/4279.pdf

Stone, D. (2012). Policy paradox: The art of political decision making (3rd ed.). New York, NY: W. W. Norton \& Company.

Underwood, E. D., \& Frey, L. R. (2008). Communication and community: Clarifying the connection across the communication community. In Beck C. S. (Ed.), Communication yearbook (Vol. 31, pp. 370-418). New York, NY: Lawrence Erlbaum Associates. 


\section{Author Biographies}

Amber NW Raile is an associate professor in the Jake Jabs College of Business \& Entrepreneurship at Montana State University. Her research focuses on the role of communication in social change. Her research has been disseminated to scholars in journals such as Politics \& Policy and Management Communication Quarterly and to practitioners through organizations such as the World Bank.

Eric D Raile is an assistant professor in the Department of Political Science at Montana State University. His research focuses on political will and public will for social change, governance and accountability issues, and the environment. His research has been funded by agencies that include the National Science Foundation and U.S. Agency for International Development and published in outlets that include Political Research Quarterly, Public Administration Review, Presidential Studies Quarterly, and Politics \& Policy.

Lori A Post is the Buehler professor Northwestern's Department of Emergency Medicine and Medical Social Sciences. She is the director of the Buehler Center for Health Policy \& Economics. Her research focuses on mobilizing and aligning public and political will for positive social change, including the removal or mitigation of underlying causes of violence against vulnerable populations. She has been funded by agencies that include the Departments of Defense, Justice, Health \& Human Services, AHRQ, USAID, and the Centers for Disease Control and Prevention. Her work has been published in JMIR Medical Informatics, Interpersonal Violence, and Politics \& Policy. 